\title{
DUZENTOS ANOS DE 1817: CAMINHOS HISTORIOGRÁFICOS E ALGUMAS DISCUSSÕES SOBRE A REVOLUÇÃO PERNAMBUCANA
}

\author{
Breno Gontijo Andrade ${ }^{1}$
}

Por que em duzentos anos, a produção historiográfica sobre a Revolução Pernambucana de 1817 sempre foi tão diminuta se se comparar, por exemplo, à produção vultosa sobre a Inconfidência Mineira? Há alguma expectativa para o aumento da produção sobre a Revolução Pernambucana para os próximos anos? O que o presente quer saber sobre 1817? Aliás, o presente quer saber sobre 1817 ? O que cada época ao longo destes duzentos anos perguntou a 1817? Por fim, qual a relevância deste estudo para a história? Para a última pergunta, podem-se tomar algumas palavras emprestadas de José Carlos REIS:

Os historiadores reescrevem continuamente a história. E o fazem talvez por duas razões principais: em primeiro lugar, pela especificidade mesma do objeto do conhecimento histórico - os homens e as sociedades humanas no tempo [...]. A história só se torna apreensível com a sucessão temporal [...]. Em segundo lugar, a história é reescrita porque o conhecimento histórico muda, acompanhando as mudanças da história. Novas fontes, novas técnicas, novos conceitos e teorias, novos pontos de vista levam à reavaliação do passado e das suas interpretações estabelecidas. ${ }^{2}$

Desse modo, para se compreender a história da Revolução Pernambucana é necessário observar como ela foi escrita ao longo do tempo, quais foram as indagações que marcaram o estudo do tema, quais as respostas encontradas. Nas palavras de Reinhart Koselleck, "[...] novas experiências se agregam, antigas são ultrapassadas, novas expectativas se abrem. Logo colocam-se novas questões em relação ao passado, que nos levam a repensar a história, a observá-la sob outros olhos, a demandar novas investigações"3. Por isso, a Revolução Pernambucana, bem como os seus estudiosos dos dois últimos séculos merecem ser revisitados, merecem que suas vozes sejam novamente ouvidas para que haja uma nova compreensão sobre 1817 e sobre o nosso próprio tempo.

O flerte de Clio com a Revolução Pernambucana foi mais intenso no século XIX, pelo fato de ter havido maior produção historiográfica sobre 1817. Os principais

\footnotetext{
${ }^{1}$ Doutorando em História pela Universidade Federal de Minas Gerais. Professor de História no Ensino Fundamental e Médio da rede privada de Divinópolis (MG). E-Mail: <brenohistoria@gmail.com>.

${ }^{2}$ REIS, José Carlos Reis. As identidades do Brasil: de Varnhagen a FHC. Rio de Janeiro: FGV, 2007, p. 9-10.

${ }^{3}$ KOSELLECK, Reinhart. Futuro passado: contribuições à semântica dos tempos históricos. Rio de Janeiro: Contraponto, 2012, p. 160.
} 
cânones são desse período como, por exemplo, o livro de viagens do francês Louis François Tollenare, que participou do movimento e escreveu no calor das lutas. Também foi produzida uma biografia onomástica dos participantes de 1817 por Joaquim Dias Martins. Embora o autor não tenha participado da Revolução como L. F. Tollenare, Joaquim Dias Martins era contemporâneo do movimento, e compôs a sua obra valendo-se da história oral, bem como de documentos que encontrou. Francisco Muniz Tavares foi um pouco dos dois autores que o precederam: viveu o movimento e conversou com seus coetâneos - embora o autor tenha deixado o tempo sedimentar suas percepções do levante e só depois de 23 anos, em 1840, publicar a sua obra sobre a Revolução Pernambucana.

Além desses três importantes observadores, não se podem esquecer outros autores que narraram brevemente suas impressões sobre 1817, cujos nomes não chegaram aos nossos dias. Os textos desses observadores estão nos Documentos históricos $-a$ Revolução de 1817, coletânea de todos os documentos que existiam na Biblioteca Nacional sobre o referido movimento, reunidos e publicados em nove volumes, entre 1953 e 1955. O interessante desses observadores anônimos está no fato de alguns deles terem apoiado os revolucionários e outros os realistas. Dessa maneira, é possível notar como os próprios revolucionários escreviam a história de 1817 e como os realistas que combatiam a Revolução Pernambucana percebiam aquele levante.

A imprensa da época também produziu suas percepções sobre 1817. Há publicações de como a monarquia de Bragança tratava o levante na Gazeta do Rio de Janeiro. Outro periódico que também publicou matérias sobre 1817 foi o Correio Braziliense, escrito em Londres por Hipólito José da Costa. Vale lembrar que Hipólito José da Costa recebeu pedidos dos próprios patriotas para apoiar a Revolução de 1817, mas não o fez. Há ainda outros periódicos espalhados pelo mundo que abordaram a Revolução de 1817 em suas páginas, como jornais dos Estados Unidos, Argentina, países europeus e até da Rússia. Muitos desses periódicos apenas repetiam as notícias publicadas pelos Estados Unidos e Inglaterra, tendo apenas o trabalho de traduzir a matéria para o seu idioma. Um estudo que observa a maioria desses jornais foi feito pelo diplomata e historiador Gonçalo Mourão, em seu livro A Revolução de 1817 e a história do Brasil.

Há ainda outro observador não menor que os já citados: o advogado dos revolucionários de 1817. Capturados pelas tropas do Conde dos Arcos, os revolucionários ficaram encarcerados durante anos. O advogado Luiz de Brito Aragão $e$ Vasconcelos foi chamado para defendê-los com o intuito de provar a inocência dos envolvidos, evitando que fossem mortos pelo crime de lesa-majestade. Aragão $e$ Vasconcelos, ao longo dos anos, vai tentar responder às principais perguntas que os realistas faziam sobre 1817, dando um viés protecionista aos acusados, como era de se esperar de um advogado de defesa. A argumentação de Aragão e Vasconcelos deve ser tomada com bastante cuidado, uma vez que seu objetivo era proteger os réus. Todavia, as defesas de Aragão e Vasconcelos são de suma importância, pois elas revelam as impressões da época sobre 1817, as dúvidas e algumas hipóteses. Além disso, ao menos quatro volumes dos nove publicados pela Biblioteca Nacional acerca da Revolução Pernambucana são sobre a argumentação utilizada pelo advogado na defesa dos réus. 
Há outros autores que publicaram no século XIX sobre 1817, mas que se dedicaram menos tempo ao tema. É o caso de Francisco Augusto Pereira da Costa, que pretendeu escrever toda a história de Pernambuco, de 1493 até 1850, dedicando parte do volume 7 à Revolução Pernambucana de $1817^{4}$. Há alguns textos de Manuel de Oliveira Lima que tratam en passant de 1817 ou de Maximiano Lopes Machado que escreveu a introdução da História da Revolução de Pernambuco em 1817, de Francisco Muniz Tavares. Há ainda artigos dispersos publicados pelo Instituto Histórico Geográfico Brasileiro (IHGB), como também artigos publicados pela revista do Instituto Arqueológico, Histórico e Geográfico Pernambucano (RIAHGP). Esses primeiros relatos, estudos e trabalhos de historiadores do século XIX são como a camada principal que envolve a Revolução Pernambucana de 1817.

Ao tratar sobre 1817, o historiador não pode perder de vistas as abordagens das escolas historiográficas de cada época, bem como a região onde os trabalhos foram escritos. Tratar da região em que essas obras e textos foram escritos tem relação com o olhar dos observadores de 1817: se é da antiga sede do Império, se é de Recife. Comparar as visões de textos historiográficos produzidos no Rio de Janeiro com os do Recife pode revelar projetos políticos por detrás dos discursos de um lado ou de outro. Reinhart Koselleck diz que um acontecimento pode ser entendido de maneira diversa, $[. .$.$] a história de um mesmo povo será diferente na Ásia e na Europa"$ Contudo, um momento histórico só pode bem entendido quando comparado sob diferentes óticas regionais e temporais. Um trabalho que pode evidenciar essas diferenças são os escritos de Francisco Adolfo Varnhagen sobre 1817. Sua ojeriza pelo movimento é amplamente conhecida. O referido historiador, de acordo com José Carlos Reis, era um homem do Império, que em 1841 adotara a nacionalidade brasileira. Queria Varnhagen contribuir na construção da identidade do Império, era fiel à família real portuguesa e até chegou a defender em armas D. Pedro I na ocasião em que o imperador fora disputar o trono com D. Miguel em Portugal ${ }^{6}$. O desprezo de Varnhagen por 1817 explica-se, em parte, por que a Revolução Pernambucana foi um movimento que tentou romper laços com o Império português, na ocasião governado por D. João VI. Para Varnhagen, D. João VI foi modelo de soberano, que amava os seus súditos, que trouxera melhorias para a antiga colônia. Esse rei teria sido responsável pela fundação das bases do Império e por tornar o Rio de Janeiro a sede do Império. A Revolução de 1817 , nessa visão, não passava de uma tentativa petulante e ingrata de separar Pernambuco da porção atlântica desse Império. Varnhagen acreditava que separar era fácil, enquanto unir era difícil ${ }^{7}$. Ao tratar do tema, já conclama o leitor a decidir-se:

Ao sensato leitor brasileiro que tenha refletido no estado próspero do Brasil, [...] deixamos que sinta e decida em consciencia se lhe parece que haveria motivos para que, em

\footnotetext{
${ }^{4}$ Embora tenha publicado no século XIX e no início do século XX, seus textos foram reunidos somente em 1951.

${ }^{5}$ KOSELLECK, Futuro passado..., p. 173.

${ }^{6}$ REIS, As identidades do Brasil.., p. 25.

${ }^{7}$ REIS, As identidades do Brasil..., p. 46-47.
} 
alguma extensão maior do Brasil, se intentasse uma revolução contra o benéfico Sr. D. João e contra a integridade do seu predileto reino de novo criado. ${ }^{8}$

Em seguida, sua fidelidade à monarquia fica mais clara, demonstrando que um projeto republicano como o proposto em 1817 por Pernambuco era um acontecimento aviltante que deveria ser esquecido:

Entretanto uma revolução, proclamando uma república absolutamente independente da sujeição à corte do Rio de Janeiro, rebentou em Pernambuco em março de 1817. É um assunto para o nosso ânimo tão pouco simpático que se nos fora permitido passar sobre ele um véu, o deixaríamos fora do quadro que nos propusemos traçar. Forçados, porém a dedicar-lhe algumas linhas, procuraremos ser breves. ${ }^{9}$

A obra de Varnhagen foi publicada entre 1854 e 1857. Mas quem, em pleno Império, teria coragem de contrariar a interpretação do chamado Heródoto do Brasil sobre 1817, isto é, um asqueroso projeto de república, rebelde, que pregava a fragmentação? Como afirma Reinhart Koselleck, "[...] todas as histórias foram constituídas pelas experiências vividas e pelas expectativas das pessoas que atuam ou que sofrem" ${ }^{\prime 10}$. Fato idêntico passava-se com Varnhagen - e outros observadores havia a expectativa de que o Brasil fosse um Império sob a coroa e o cetro monárquicos.

Mesmo assim é possível lançar uma indagação: houve alguma contestação no Recife sobre a interpretação de Varnhagen? Para se responder a essa dúvida, seria necessário, por exemplo, pesquisar ao menos nas revistas do Instituto Arqueológico, Histórico e Geográfico Pernambucano. Sabe-se que a revista do referido Instituto foi publicada pela primeira vez em 1863, ou seja, quase seis anos depois da publicação da obra de Varnhagen. Numa observação menos detalhada, nos primeiros anos de sua publicação, não há nenhuma referência sobre 1817 publicada na revista. Esse silêncio é revelador e merece ser questionado, afinal, o presidente do IAHGP naquele momento era Francisco Muniz Tavares, participante da Revolução de 1817. Queria o antigo revolucionário esquecer o que ocorrera em 1817 a bem da união das províncias ao Império, já que o imperador, D. Pedro II, era presidente honorário do IAHGP? Talvez, não. Muniz Tavares publicou sua obra sobre a Revolução em 1840, muitos anos antes de Varnhagen agir como juiz e condenar o levante republicano de Pernambuco. O fato de Muniz Tavares escrever sobre 1817 não seria reviver a Revolução, com os olhos do presente, isto é, o presente de 1840? Se assim fosse, por que queria reviver a Revolução, por que escreveu naquele momento $e$, não, em outro? Não seria melhor esquecê-la? Sob quais circunstâncias Muniz Tavares escreveu

\footnotetext{
${ }^{8}$ VARNHAGEN, Francisco Adolfo. História geral do Brazil. Rio de Janeiro: Caza de L. e H. Laemmert, 1854, p. 373.

${ }^{9}$ VARNHAGEN, História geral do Brazil, p. 373.

${ }^{10}$ KOSELLECK, Futuro passado..., p. 306. 
sua obra? A forma da sua escrita narrava acontecimentos de maneira mais crítica, ou evocava aquele momento como heroico? Uma resposta geral pode ser esboçada: o momento da publicação da obra de Muniz Tavares coincide com um período histórico bastante conturbado, o período regencial com pelo menos cinco revoltas em menos de dez anos. Assim, quais respostas 1817 poderiam dar para os homens da década de 40 do século XIX?

Depois das discussões de meados do século XIX, parece que houve um vácuo sobre a produção historiográfica relacionada a 1817. Sempre existiu um artigo disperso aqui ou acolá, mas uma obra dedicada ao movimento, tal como a de L. F. Tollenare, Joaquim Dias Martins e Francisco Muniz Tavares, não foi escrita nesse período. Mesmo o ano do centenário da Revolução, em 1917, não vai atrair historiadores para o tema. Talvez por ser um ano de tensão, que trazia o cheiro nauseabundo da morte, tanto pelos mortos da $1^{\text {a }}$ Guerra Mundial quanto pelo aparecimento da gripe espanhola no Brasil. Os historiadores estariam preocupados com outras questões, ou mesmo achavam que a história sobre a Revolução Pernambucana já havia sido toda escrita pelos três autores citados? De qualquer maneira, o IAHGP organizou no ano do centenário da Revolução uma revista que tratava somente sobre 1817, além de republicar o livro de Muniz Tavares sobre a Revolução. A escolha da obra de Muniz Tavares em 1917 não foi fortuita. Pode-se arriscar que, ao escolher aquele livro, o IAHGP, pernambucanos e estudiosos estavam coroando o pernambucano Muniz Tavares como o Heródoto de 1817, ou melhor, como Tucídides de 1817, afinal, Tavares não só ouviu falar, mas participou do movimento e escreveu sobre ele. Haveria melhor testemunha, melhor obra sobre 1817 que a do pernambucano Muniz Tavares, o padre guerrilheiro? A tendência da época era valorizar a testemunha ocular, o que levava a obra de Joaquim Dias Martins para um plano inferior, já que seus escritos se pautavam, em boa parte, no ouvir dizer. Havia a obra do viajante L. F. Tollenare, que participou do movimento $e$ escreveu no calor da luta, entretanto a obra do referido autor na ocasião não era tão conhecida e o olhar de um ex-revolucionário, certamente, era mais valorizado do que as percepções de um viajante francês que estava apenas de passagem por Pernambuco e que criticou a Revolução.

As revistas do Instituto Arqueológico, Histórico e Geográfico Pernambucano (RIAHGP) mencionam a intenção de mandar publicar todos os documentos ou, ao menos, os documentos inéditos relativos a 1817. A publicação central, porém, diz a revista, deveria ser a obra de Muniz Tavares - esgotada - com alguns documentos em anexo ${ }^{11}$. Menciona também a dificuldade em conseguir recursos para a reimpressão da obra de Muniz Tavares e para organizar as solenidades do dia 6 de março. Pediram recursos para os Estados e Municípios que tiveram alguma ligação histórica com a Revolução, sem se esquecer de pedir recursos aos abastados dessas regiões. Se no campo da história não se encontrava o ânimo de estudiosos em escrever sobre 1817, no campo político há certa ansiedade em querer comemorar a data centenária. A intenção do IAHGP era organizar um campeonato interestadual de futebol em Pernambuco, fundar escolas em todos os municípios com o nome dos revolucionários ${ }^{11}$ IAHGP - Instituto Arqueológico, Histórico e Geográfico Pernambucano. "Edição comemorativa do $1^{\circ}$
centenário da Revolução Republicana de 1817". Revista do IAHGP, Recife, 1918, p. 2-5. 
de 1817, "[...] para que a liga contra o analfabetismo seja instalada com elevado número de escolas", colocar a bandeira dos revolucionários de 1817 como a bandeira oficial do Estado, tornar o dia 6 de março feriado nacional, entre outros pedidos ${ }^{12}$. Além disso, foi aberto concurso público para a criação de um monumento que representasse 1817, concorrendo vários escultores, estrangeiros e nacionais. De acordo com a revista, o artista deveria entender que:

A república de 1817 não foi portanto simplesmente demolidora, mas também construtora, tendendo a pôr em prática os princípios da Revolução Americana e da Revolução Francesa, que estavam servindo de guia ao ingente esforço libertador desenvolvido pela América Espanhola uma luta extrema. Em todas estas considerações se deverá inspirar o artista que concorrer ao monumento destinado a recordar a data gloriosa que marcou no Brasil o advento da democracia. $^{13}$

Desse modo, a revista parece responder, mesmo que tardiamente, às críticas de Varnhagen, que julgavam 1817 como movimento sedicioso, ingrato, que queria apartar uma região do Império português. Para a revista, se 1817 foi por um lado uma revolução demolidora, por outro ela também foi construtora ao colocar princípios da Independência dos EUA e da Revolução Francesa em prática. Assim, a revista tem uma visão otimista sobre 1817 , considerando aquela data como o marco principal do advento da democracia no Brasil. Queria a revista defender a ideia de que a Revolução Pernambucana era um dos movimentos responsáveis ideologicamente pela jovem república que viviam naquele centenário?

De qualquer forma, o ânimo pernambucano transbordava das páginas da revista $e$ concretizava-se. O presidente Wenceslau Brás chegou a permitir que aquele dia 6 de março de 1917 fosse feriado nacional. Todo esse frisson relatado pela revista deixava claro que a Revolução de 1817 era ainda muito presente no imaginário pernambucano, mobilizando pensamentos e símbolos. Em discursos da época, uma leitura possível era a associação de 1817 como um movimento genuinamente republicano que tinha vínculos diretos com a Proclamação da República em 1889:

A 19 de maio do ano de 1817 era definitivamente abafada a semente republicana e presos os principais chefes do patriótico e glorioso movimento. Não contavam, pois, os déspotas de então que o sangue daqueles bravos fecundaria a terra que lhes serviu de berço frutificando em 1889 a semente que haviam semeado com tanta coragem e tanto sacrifício. ${ }^{14}$

\footnotetext{
${ }^{12}$ IAHGP, "Edição comemorativa...", p. 13.

${ }^{13}$ IAHGP, "Edição comemorativa...", p. 15.

${ }^{14}$ IAHGP, "Edição comemorativa....", p. 20. 
Portanto, nota-se um esforço em deixar claro que Pernambuco era o reduto mais antigo do pensamento republicano do Brasil, que só conseguiu vingar no restante do país 72 anos depois. O governo federal do início do século XX tinha o interesse em fortalecer a ideia de que a república era um sistema de governo melhor que a monarquia. Basta lembrar que, além de atender às necessidades comemorativas de Pernambuco, a família real ainda estava banida do território brasileiro.

Entretanto, uma pergunta parecia incomodar os editores da RIAHGP: o movimento de 1817 queria levar Pernambuco à independência e separar-se do Brasil? A revista responde que sim e que não. Havia alguns revolucionários mais exaltados que queriam levar a Revolução às últimas consequências e separar a porção norte do restante do Brasil. Todavia, os principais revolucionários que lideraram o movimento percebiam que essa ideia não se sustentava:

O padre João Ribeiro, a mais notável e a mais tocante das personagens da revolução, teve a pronta intuição de que era pouco viável a organização autônoma de tantas pequenas repúblicas. Elas deviam formar constelação, ligar-se por laços políticos indissolúveis e consagrar essa união erigindo uma capital geograficamente central. ${ }^{15}$

Portanto, a revista defendia o discurso de que Pernambuco, embora rebelado, não queria tornar-se independente sozinho, mas queria unir-se a outras províncias, unidas por laços políticos indissolúveis. $\mathrm{E}$, se voltarmos ao tempo, será que a leitura que 1917 faz de 1817 procede, isto é, as fontes dizem que os revolucionários de fato não queriam separar-se da América portuguesa? Estariam eles interessados num projeto republicano para toda a América portuguesa ou somente para Pernambuco e capitanias vizinhas?

A revista busca ainda responder outras questões do seu tempo sobre a Revolução de 1817, evidenciando como aquele movimento era imaginado quase um século depois de seu aparecimento. Queriam entender, por exemplo, se houve planejamento da Revolução, se havia sentimento de nacionalidade em 1817, se o pouco derramamento de sangue colocava o movimento acima de outras contestações, se 1817 fora um movimento local ou supranacional, se a manutenção da escravidão em 1817 afetava a Revolução, etc.

Depois da produção da revista comemorativa de 1917 com suas 530 páginas, 1817 voltou ao limbo do esquecimento, novamente, com um ou outro artigo gotejando ao longo das décadas. Por que esse esquecimento insistente? Koselleck explica a intencionalidade dos esquecimentos dizendo que uma sociedade pode esquecer passados sempre presentes, abandonar projetos, propor outras esperas. $\mathrm{O}$ objetivo das sociedades é construir a ação que as levará ao futuro, assim elas não podem realizar suas metas apenas do presente para o futuro, precisam sempre fazer um recuo estratégico ao passado ${ }^{16}$. Portanto, esquecer-se de um acontecimento $e$

\footnotetext{
${ }^{15}$ IAHGP, "Edição comemorativa...", p. 43.

${ }^{16}$ REIS, José Carlos. Teoria e História: Tempo Histórico, História do Pensamento Histórico Ocidental e pensamento brasileiro. Rio de Janeiro: FGV, 2012, p. 44.
} 
lembrar-se de outro é uma seleção do presente que aponta para um projeto de futuro. $\mathrm{O}$ que foi lembrado no lugar de 1817 ao longo do século XX?

A próxima publicação de vulto foi feita entre 1953-1955 pela Biblioteca Nacional, os chamados Documentos Históricos. O prefaciador dos nove volumes publicados em 2.551 páginas foi José Honório RODRIGUES, diretor da Seção de Publicações e Obras Raras ${ }^{17}$. Ao início de cada volume, José Honório fazia uma apresentação dos documentos e, em seguida, tecia reflexões sobre o tema. Uma dessas reflexões está no volume $\mathrm{CI}$, em que o autor procura identificar se 1817 era um movimento nacional ou não. José Honório chega à conclusão de que 1817 foi um movimento nacional, "[...] um marco de extraordinária significação, pelo revigoramento do espírito nacional e pela iniciativa prática que lhe coube na preparação da Independência" ${ }^{18}$. Procurou também entender as causas da Revolução e rompeu com as hipóteses de Muniz TAVARES, que diziam que o levante teve como um de seus motivos os abusos dos portugueses que, ao longo do tempo, causara rancor nos brasileiros e desejo de saírem da posição de inferioridade. Para José Honório RODRIGUES:

Não foi o ódio contra os portugueses, nem contra os reinóis prepotentes a causa imediata da rebeldia, como parece crer grande parte de nossa historiografia, baseada na ordem do dia de 4 de março de 1817 e na interpretação contemporânea de Muniz Tavares, o cronista da Revolução. Os portugueses, diz este, reputavam-se únicos senhores do país, que os acolhia e os elevava: nascer brasileiro era um título de inferioridade. Se devemos considerar a Independência como a tradução da consciência de superioridade a Portugal, como queria Capistrano de Abreu, a Revolução de 1817, cinco anos antes, representa a primeira emoção de superioridade, a primeira revelação de um sentimento nacional de responsabilidade, o nascimento da decisão de criar uma nação livre, independente, inspirada em ideologia universal, animada pela fé irredutível no progresso humano, que o 7 de setembro veio a consagrar com a independência $e$ as garantias constitucionais. ${ }^{19}$

Portanto, à primeira vista, José Honório Rodrigues consegue romper com uma das hipóteses de Muniz Tavares. Para o diretor da Biblioteca Nacional, um dos motivos para a ruptura com o Império Português foi o sentimento de superioridade pernambucana, que nada mais é do que expressão do sentimento nacional, o desejo

\footnotetext{
${ }^{17}$ A publicação dos Documentos Históricos iniciou-se em 1928 e terminou com a publicação de 110 livros, dos quais os dez últimos eram sobre a Revolução Pernambucana e sobre a Conspiração dos Suassuna. As publicações cessaram em 1955 e foram retomadas de maneira bastante tímida em 20112012, com a publicação dos volumes 111 e 112.

18 “A REVOLUÇÃO de 1817”. Documentos Históricos. Rio de Janeiro, Biblioteca Nacional, 1953-1955, vol. CI, p. I.

19 "A REVOLUÇÃO de 1817", p. II. 
de criar uma nação livre. A escrita de Honório Rodrigues relaciona-se intimamente com a sua época. O Brasil passava por uma onda nacionalista nos anos 1950 que motivava os intelectuais a debaterem sobre a gênese da nação e a "evolução da consciência nacional". Natural que Honório Rodrigues escolhesse documentos que se relacionavam à independência para ser publicados, por isso a escolha sobre 1817 e, não, outros tipos de documentos, como os relativos à Guerra do Paraguai, publicados somente em 2012. A escrita de Honório Rodrigues também revela a preocupação com a descrição, com o factual, com a tentativa de apresentar 1817 como um movimento pré-independência que dialogava com outros movimentos como a Inconfidência Mineira e a Conjuração Baiana, como se houvesse elementos históricos interligados que culminassem em um despertar da consciência nacional que acabaria levando à independência.

Apesar de José Honório Rodrigues escrever sobre 1817 no início de cada coletânea de documentos sobre o período, ele não se dedicou tal como os observadores do século XIX a examinar detalhadamente o movimento pernambucano. Dedicou, como outros de sua época, poucas páginas ao estudo de 1817. Foi somente na segunda metade do século XX que um historiador de renome se ocupou de 1817. Seu nome é Carlos Guilherme Mota e escreveu Nordeste 1817: estruturas e argumentos.

Carlos Guilherme Mota publicou sua obra em 1972, dedicando quase trezentas páginas sobre o estudo de 1817. Embora o autor tenha uma clara preocupação em entender as mentalidades de 1817 - portanto, um viés mais próximo dos postulados dos Annales - será a abordagem marxista que ele tenta evitar a principal característica de sua obra.

Primeiramente, Guilherme Mota não rompeu com a percepção historiográfica sobre 1817 vigente: de que foi um movimento ligado a outras inconfidências que ajudaram a despertar a "consciência nacional" culminando, enfim, na independência de $1822^{20}$. A sua pesquisa se pautou também na comparação de $1817 \mathrm{com}$ a Inconfidência Mineira e a Conjuração Baiana ${ }^{21}$. Contudo, trata 1817 como um movimento insurrecional:

$O$ ano de 1817 registra para o Nordeste um amplo movimento insurrecional - não ousaríamos dizer revolucionário - ao qual não estiveram indiferentes as massas populares. Não se trata mais também, de movimentos circunscritos aos núcleos urbanos, ou às elites insatisfeitas com o peso da tributação. Um projeto revolucionário foi esboçado e tentou-se a desarticulação da ordem escravocrata, sem êxito: o poder foi tomado a 06 de março e, em Recife, polo dinamizador de vasta hinterlândia, os insurgentes

\footnotetext{
${ }^{20}$ MOTA, Carlos Guilherme. Nordeste 1817: estruturas e argumentos. São Paulo: Perspectiva, 1972, p. 1.

${ }^{21}$ MOTA, Nordeste $1817 \ldots$, p. 4.
}

SAECULUM - Revista de História [36]; João Pessoa, jan./jun. 2017. 
permaneceram 74 dias na direção da "república", operando no núcleo dos encadeamentos em curso. ${ }^{22}$

Desse modo, o primeiro problema que incomodou Guilherme Mota ao longo de sua obra e que não foi explorado pelos seus antecessores era a natureza revolucionária de 1817, afinal, aquele movimento foi de fato uma revolução? Guilherme Mota diz que 1817 não pode ser considerado uma revolução, no máximo um movimento insurrecional. Definia como movimento insurrecional, porque "[...] nenhuma alteração essencial foi notada no nível das relações de produção: pelo contrário, a independentização relativa dos setores ligados à grande propriedade pressupunha como requisito básico a manutenção da ordem escravocrata" ${ }^{23}$. Utilizando o mesmo raciocínio, pensando nos anos em que vivia Carlos Guilherme da Mota, não estaria o historiador querendo responder a outra questão do seu próprio tempo, se o ano de 1964 teria sido um golpe ou uma revolução? Não estaria Carlos Guilherme da Mota querendo perceber se, depois de 1964, houvera alteração nas relações de produção para aí entender 1964, se fora um golpe ou uma revolução?

Além desse problema, Guilherme Mota busca responder a outras questões que podem ser observadas no excerto: 1817 fora um movimento rural ou urbano; com participação das massas ou da elite; como os revolucionários tratavam a escravidão; houve a constituição de uma república ou não? De qualquer modo, o estudo de Guilherme Mota traz a sua parcela de inovação. Foi o primeiro trabalho que se preocupou em estudar o vocabulário utilizado pelos revolucionários. O historiador pesquisou o significado de revolução e também o significado de classe. Sobre o último termo, dedicou quase quarenta páginas de seu livro.

Alguns anos mais tarde, 1817 contaria com outro estudo importante. Em 1987, Glacyra Lazzari Leite publicou o Pernambuco 1817: estrutura e comportamentos sociais, como parte de sua tese de doutorado. O prefaciador da obra, Manuel Correia de Andrade, aprecia o livro por ele não só revelar a crise do antigo sistema colonial, como também a crise econômica brasileira dos anos 1980. De acordo com o historiador, aquela obra ajudava a compreender a

[...] problemática atual e um elemento para a solução da crise em que vivemos, que, além de econômica é social e política. Isto porque a crise atual é, em grande parte, o resultado de um processo que se iniciou com a implantação da colonização portuguesa no Brasil e com a permanência de muitas das estruturas, então implantadas e desenvolvidas, adaptadas, com pequenas modificações, aos desafios que se apresentam. Os grupos e classes dominantes têm, até hoje, conseguido, com a cooptação de alguns elementos oriundos das classes dominadas, manter um sistema profundamente favorável a

\footnotetext{
${ }^{22}$ MOTA, Nordeste $1817 \ldots$, p. $1-2$.

${ }^{23}$ MOTA, Nordeste 1817..., p. 286.
} 
uma forte estratificação social, ligada a uma estratificação étnica e cultural. ${ }^{24}$

Assim, o prefaciador da obra de Glacyra Lazzari Leite trata 1817 como episódio que pode esclarecer muito da crise econômica que o país vivia na década de 1980, lançando luz não só sobre a economia, mas, também, sobre aspectos sociais $e$ políticos. Manuel Correia de Andrade, nas entrelinhas, percebe que em 1817 foram as classes dominantes que conduziram um movimento falho, enquanto naqueles anos em que ele escrevia, o Brasil encontrava-se em crise econômica porque, novamente, as elites conduziam os rumos do país. Como em 1817, as elites nos anos 1980 também cooptavam os elementos das classes dominadas, reverberando a estratificação da sociedade. O que Manuel Correia de Andrade - que foi comunista e perseguido político em 1944 e 1964 - disse é que o Brasil só poderia sair da crise dos anos 1980 quando a sociedade brasileira fosse menos estratificada, ou mesmo, se as classes dominantes perdessem espaço para as classes dominadas. Numa palavra, para se entenderem os problemas dos anos 1980 era necessário recorrer às lições, sobretudo, às falhas de 1817 - Historia magistral vitae est.

$\mathrm{Na}$ introdução de sua obra, Glacyra Lazzari Leite aponta para essa direção, diz que o seu trabalho buscava entender as interferências da crise do antigo sistema colonial sobre a economia pernambucana, de como essa crise interferiu nas relações econômico-sociais ${ }^{25}$. A principal tese defendida pela autora é que a Revolução Pernambucana ocorreu em resposta à crise do antigo sistema colonial. Nesse sentido, a autora está mais preocupada em responder quais foram as causas de 1817. Passado o período napoleônico, o governo português e os comerciantes lusitanos lutavam para readquirir suas posições perdidas. Essa disputa acabou gerando rivalidades em Pernambuco entre brasileiros, os produtores do açúcar $e$ do algodão $e$ dos portugueses que comercializavam essa produção e ficava com a maior parte dos lucros. Essas rivalidades acabaram provocando a Revolução ${ }^{26}$. Se se observar a obra da autora como um todo, o diálogo que ela estabelece é principalmente com Carlos Guilherme Mota, debruçando-se em causas econômicas para a Revolução, disputas de classes e crise do antigo sistema colonial, problemas que Carlos Guilherme da Mota tenta abordar de uma maneira menos marxista.

Depois das publicações de Carlos Guilherme Mota e Glacyra Lazzari Leite, não houve nenhuma obra dedicada à Revolução Pernambucana. Observa-se ainda que depois do centenário na Revolução somente estudiosos do sudeste se dedicaram a desvendar 1817. Por que os pesquisadores do atual nordeste, sobretudo, pernambucanos e paraibanos, não deitaram seus olhos sobre 1817? Onde estão as grandes obras sobre o movimento escritas por nordestinos? A produção sobre 1817 coordenada pelo sudeste, mesmo que pequena, não indicaria uma percepção mais enviesada, uma leitura dos vencedores?

\footnotetext{
${ }^{24}$ ANDRADE, Manuel Correia de. Prefácio. In: LEITE, Glacyra Lazzari. Pernambuco 1817: estrutura e comportamentos Sociais. Recife: Massangana, 1988.

${ }^{25}$ LEITE, Pernambuco $1817 \ldots$... p. 18.

${ }^{26}$ LEITE, Pernambuco $1817 . . .$, p. $77-83$.
} 
Evaldo Cabral de Mello, pernambucano, tardiamente aparece com uma visão diferente daquelas produzidas pelo sudeste. Embora ainda não tenha deixado uma obra sobre 1817, dedicou um capítulo de livro ao movimento em questão. Além disso, o título do seu livro aponta para a construção de uma hipótese sobre o que significou a Revolução Pernambucana de 1817 e a Confederação do Equador de 1824: outro projeto de independência ${ }^{27}$. No prefácio de sua obra, Evaldo Cabral de Mello diz que a fundação do Império ainda hoje é uma história contada sob a ótica do Rio de Janeiro, numa versão que defende a união nacional, sob vultos dos nascidos no atual Sudeste ${ }^{28}$. Essa provocação do autor pernambucano é inovadora, pois aventa a hipótese de que a história tanto da Revolução Pernambucana quanto das origens do Império foi forjada pelo sudeste. Para Evaldo Cabral de Mello, 1817 foi movimento precursor de uma tendência observada em outras capitanias do Brasil: a busca por uma maior autonomia das elites provinciais dos centros de poder Lisboa e Rio de Janeiro. No caso de Pernambuco, a proposta era mais radical, de autonomia definitiva dos mandos da monarquia, à semelhança de outros países da América Espanhola que buscavam o rompimento com a Espanha. Por outro lado, se Pernambuco defendia essa proposta de ruptura, a interiorização da Metrópole veio fortalecer esta alternativa: refundação do Império português com sede na América Portuguesa. Contudo, conclui Evaldo Cabral de Mello havia um descompasso entre os projetos de independência do norte - ruptura definitiva com criação de um sistema de governo republicano - $e$ o projeto do sul - refundação do Império Português no Brasil com sistema de governo monárquico. A proposta do norte foi derrotada em $1817^{29}$.

O autor ainda aprofunda o estudo da proposta de autonomia formulada em Pernambuco e encontra suas origens nos séculos anteriores, na expulsão dos holandeses. Todavia, essa proposta se fortalece no século XIX, pela presença da maçonaria, atuante tanto na Conspiração dos Suassuna em 1801 - conspiração esta questionável quando exposta sob a luz da documentação existente - quanto na Revolução de 1817.

No primeiro capítulo do seu referido livro, Evaldo Cabral de Mello apresenta a Maçonaria, recém-instalada em Pernambuco, como força-motriz da Revolução. Autores anteriores conheciam a importância da Maçonaria, mas foi Evaldo Cabral de Mello que a transformou em carro-chefe da Revolução. A ênfase de Evaldo Cabral de Mello na Maçonaria concorda sem pestanejar com a explicação que os realistas que combateram os patriotas encontraram para justificar 1817: a Maçonaria era responsável pelos males de um lado e de outro do oceano, tanto articulando a conspiração de Gomes Freire quanto a Revolução Pernambucana, ambas ocorridas no mesmo ano. Entretanto, a diferença do historiador para os realistas é que Evaldo Cabral de Mello acredita que as lojas maçônicas que atuaram em Pernambuco não

\footnotetext{
${ }^{27}$ MELLO, Evaldo Cabral de. A outra independência: o federalismo pernambucano de 1817 a 1824 . São Paulo: Editora 34, 2004.

${ }^{28}$ MELLO, A outra independência..., p. 11.

${ }^{29}$ Com o fim da Revolução Pernambucana de 1817, a disputa começou a ser outra. Rio de Janeiro, como nova sede do Império português, rivalizou com Lisboa, antiga sede desse Império. Ambas as cidades disputavam a preferência política das províncias no Brasil, episódio este que se envolve com a Revolução do Porto, com as deliberações das Cortes de Lisboa e com a Independência do Brasil.
} 
tinham relações com as lojas maçônicas de Portugal, ao passo que os realistas percebiam a Maçonaria como uma instituição coesa, cujo intuito era derrubar a monarquia. De qualquer modo, tanto o historiador quanto os antigos realistas não têm dúvidas da articulação maçônica por detrás dos movimentos.

Além da Maçonaria, Evaldo Cabral de Mello trabalha com a ideia de outros fatores que contribuíram para que a revolução eclodisse em Pernambuco. Havia a insatisfação pelos altos impostos que sangravam os cofres de Pernambuco, sendo enviados para o Rio de Janeiro sem beneficiar os pernambucanos. Não fosse a Maçonaria, a elite pernambucana jamais se haveria articulado contra a proposta intragável de refundação do Império no Rio de Janeiro, jamais se uniria a grupos de outras capitanias, como Bahia, Paraíba, Rio Grande do Norte e Ceará. A maioria dos autores que escreveram sobre 1817 evitaram a interpretação de que a Maçonaria fora a articuladora de todo ou boa parte do levante, porque, além da carência documental que permitisse entender os meandros dessa articulação, foi uma explicação criada pelos realistas que combateram os patriotas.

Outro ponto que Evaldo Cabral de Mello busca entender, além das origens da Revolução é: por que 1817 falhou? A pergunta não é nova. Muniz Tavares debruçase sobre ela e chega à conclusão de que 1817 falhou por falta de união entre os revolucionários. Evaldo Cabral de Mello acrescenta causas geográficas para o fracasso da Revolução. A Mata Norte, também chamada de Mata Seca, não teria conseguido o apoio dos senhores de engenho da Mata Sul, também chamada de Mata Úmida. Na Mata Norte predominava o plantio do algodão, enquanto na Mata Sul o predomínio era do plantio da cana-de-açúcar. Enquanto no norte havia uma elite mais dinâmica, que mudou o plantio da cana para o algodáo, no sul a aristocracia era mais tradicional, que expandia a sua produção de açúcar, ainda que o preço do produto estivesse em baixa. No norte, Evaldo Cabral de Mello defende que havia maior concentração de população e que o trabalho livre era comum, ao contrário do sul, que estava aferrado ao trabalho escravo. Grosso modo, o autor quer dizer que a Revolução foi bem aceita no norte algodoeiro, mas, não, no sul canavieiro. Foi a aristocracia da Mata Sul, antiquada e carunchada que acabou opondo-se à Revolução defendida pelos proprietários do norte ${ }^{30}$. A hipótese demonstra que o autor não se aprofundou no estudo sobre 1817, pois explica o fracasso de uma complexa Revolução ainda pouco estudada, com métodos bastante colegiais, duais. Lembra muito as explicações escolares sobre a Guerra Civil dos Estados Unidos do norte desenvolvido e defensor do trabalho livre contra o sul latifundiário embasado no trabalho escravo. Além disso, Evaldo Cabral de Mello não faz justiça ao esquecerse de citar o verdadeiro autor dessa hipótese, historiador, geólogo que publicou inúmeros livros didáticos de história, Manuel Correia de Andrade ${ }^{31}$.

Embora numa parte desse texto haja críticas ao trabalho de Evaldo Cabral de Mello sobre 1817 - e esse fato explica-se por ele publicar trabalho contemporâneo a esse artigo - não há dúvidas sobre as suas contribuições ao entendimento do movimento. Expor 1817 e 1824 como propostas de outra independência vinda do norte é, de fato, algo que enriquece o debate. O que pode ser questionado e que faz

\footnotetext{
${ }^{30}$ Ibidem, p. 57-63.

${ }^{31}$ ANDRADE, Manuel de. A terra e o homem no Nordeste. São Paulo: Brasiliense, 1973, p. 129.
} 
parte das indagações deste artigo é, por que Evaldo Cabral de Mello, que se debruçou tanto sobre a história de Pernambuco, preferiu orientar-se por hipóteses visivelmente frágeis e genéricas? Por que um estudo tão rápido sobre 1817?

A discussão sobre 1817 é vasta e labiríntica, ainda que poucos autores tenham se dedicado ao movimento. Uma importante pergunta que Koselleck faz para si é "como, em cada presente, as dimensões temporais do passado e do futuro foram postas em relação?". Sua resposta: "determinando a diferença entre passado e futuro em um presente, é possível apreender alguma coisa que seria chamada de tempo histórico. Cada época mantém relações diferentes com seu passado e futuro, cada presente constrói ritmos históricos diferenciados ${ }^{32}$. Dessa forma, é preciso estudar mais 1817 para que os tempos históricos que perpassaram o movimento ao longo desses dois últimos séculos sejam melhor compreendidos.

\section{$\operatorname{soc}$}

\section{RESUMO}

O artigo trabalha com a produção historiográfica da Revolução Pernambucana de 1817 ao longo de quase duzentos anos. Textos dos revolucionários, realistas, viajantes, historiadores, observadores embasam o estudo. Também questiona o esquecimento da historiografia sobre a Revolução de 1817: primeiro movimento a ter sucesso em sua declaração de independência da Coroa portuguesa, primeiro movimento a buscar ajuda política, militar e econômica de outros países, primeiro movimento a criar uma préconstituição no Brasil, primeiro movimento a ter grande apoio da maçonaria e do clero que pegou em armas, primeiro movimento a ter centenas de presos acusados de crime de lesamajestade.

Palavras Chave: Revolução Pernambucana; Revolução de 1817; Historiografia.

\begin{abstract}
The article works with the historical production of Pernambuco Revolution 1817 over nearly two hundred years. Texts of the revolutionary people, royalist, travellers, historians, observers underlying the study. It also discusses the oblivion of history about the 1817 Revolution: first movement succeed in its declaration of independence from the Portuguese crown, first movement to seek help political, economic and military of other countries, first movement to create a pre-constitution in Brazil, first movement to have great support of freemasonry and the clergy who took up arms, first movement to have hundreds of prisoners accused of lese majesty crime.
\end{abstract}

Keywords: Pernambucan Revolution; 1817 Revolution; Historiography.

Artigo recebido em 11 jan. 2017.

Aprovado em 03 mar. 2017.

${ }^{32}$ REIS, José Carlos. Teoria e História: Tempo Histórico, História do Pensamento Histórico Ocidental e Pensamento Brasileiro. Rio de Janeiro: FGV, 2012. p. 41-43. 